\title{
MEDICAL MALPRACTICE RISK MANAGEMENT EARLY WARNING SYSTEMS
}

\author{
Orley H. Lindgren, ${ }^{*}$ Ronald Christensen** and Don Harper Mills***
}

\section{INTRODUCTION}

This article provides evidence that prompt incident reporting by medical professionals can serve a useful "early warning" function to identify future medical malpractice claims. Unlike traditional incident reports that focus on largely minor injuries caused by non-physician employees of medical facilities, the reporting system described in this article was designed to capture significant medical injuries before claimants' lawyers do so. Physicians helped to design this new system, which encourages prompt reporting-especially by telephone or face to face with risk managers, not merely through the conventional, standard written forms.

This article is part of a larger study of early warning, which explores how early warning is used and how it can be improved.' The main goal of the study was to confirm or deny the operative philosophy that early warning based on incident reports or occurrence reports could improve claims processing and outcomes. The data discussed here show that malpractice claims established on the basis of early warning incident reports not only involve the full range of injury severity, but also identify claims warranting substantial indemnity payments. These claims are generally brought to the

Copyright $@ 1991$ by Law and Contemporary Problems

* Ph.D., Executive Director, Institute for Medical Risk Studies, Sausalito, California; Director, Special Projects, Professional Risk Management Group, Sausalito, California.

** Ph.D., J.D., Director, Institute for Medical Risk Studies, Lincoln, Massachusetts; Adjunct Professor of Engineering, Massachusetts Institute of Technology, Cambridge, Massachusetts.

*** M.D., J.D., Medical Director, Institute for Medical Risk Studies and the Professional Risk Management Group, Long Beach/Sausalito, California; Clinical Professor, School of Medicine, University of Southern California, Los Angeles.

Generous support for this research was provided in part by the Robert Wood Johnson Foundation Medical Malpractice Program. Support as well as data on incidence and claims were provided by the Professional Risk Management Group, Sausalito/Long Beach, California. This support is gratefully acknowledged as well as is the cooperation of the County of Los Angeles and the Regents of the University of California.

1. See Orley H. Lindgren, Ronald Christensen \& Don Harper Mills, Prediction and Prevention of Medical Malpractice Claims, in Proceedings of the Department of Health and Human Services ("HHS") Research Conference on Health Care Improvement and Medical Liability (W'ashington, D.C., April 27, 1988); Laura L. Morlock. Orley H. Lindgren \& Don Harper Mills, Malpractice, Clinical Risk Management, and Quality. Assessment, in Norbert Goldfield and David B. Nash, eds, Providing Quality Care: The Challenge to Climicians 225 (Am College of Physicians, 1989); US Gen Acct'g Office, Health Care Initiatives in Hospital Risk. Management 14 (Gov't Printing Office, 1989) (GAO/HRD-89-79). 
attention of claims personnel sooner than claims first opened upon receipt of some type of legal notice. They are also closed more quickly, apparently due to the greater availability of better information on the claims. Qualitatively, risk managers believe the claims are more correctly handled. Compensation payments are comparable, while the expenses of negotiating or litigating the claims are substantially less.

The malpractice liability system is often attacked for its high costs and unduly haphazard outcomes. Based upon the work described here, many of its flaws can be ameliorated by improved claims reporting systems and claims management. Working "within the system" in this manner deserves a place on the reform agenda, alongside longer-term, more radical changes. Moreover, in the long term, good risk management reinforces the purposes of the medical facilities' quality assurance programs.

\section{II}

\section{The “Early Warning” Study}

\section{A. Traditional Incident Reports and Their Limitations}

Incident reporting systems exist in virtually all U.S. hospitals. ${ }^{2}$ Many of these traditional systems originated in the 1950s, as hospitals and their outside liability insurers became more litigation conscious. These reports were created as administrative reporting systems, during an era when hospitals were responsible only for their own employees, not for "independent contractors" such as physicians. As such, the reports typically identify mishaps involving patients or visitors that were the result of nonphysician employee actions or hospital physical plant problems. ${ }^{3}$ The reports usually provide a written description of the patient injury or mishap, compiled on a standard check-list, small-print form by nurses or other hospital employees rather than by physicians. ${ }^{4}$

Malpractice insurers are aware of these reporting systems and have made limited, educational use of summary information from them. Nursing staffs have also used the information, primarily to identify systematic risks within the hospital physical plant or nursing procedures needing correction. Nursing staffs also find the information helpful in developing educational programs for hospital employees. ${ }^{5}$

2. See generally US Congress, Office of Technology Assessment, The Quality of Wedical Care: Information for Consumers 101 (Gov't Printing Office, June 1988) (OTA-H-386) (see especially chapter on "Adverse Events"); see also US Congress, US Gen Acct'g Office, Initiatives in Hospital Risk Management (Gov't Printing Office, July 1989) (GAO/HRD-89-79).

3. The predominant "incidents" are patient or visitor slips and falls, lost patient property, and medication errors. There is evidence that incident reporting systems do better in identifying claims related to hospitals custodial functions (for example, in patient rooms) than in medical service areas (for example, emergency rooms). See Grace Duran, Positive Lise of Incident Reports. 53 Hospitals 60-68 (1979).

4. See, for example, James E. Orlikoff, William R. Fifer \& Hugh P. Greeley, Malpractice Prevention and Liability Control for Hospitals (Am Hosp Ass'n, Ist ed 1981).

5. In particular, Jack Fulton of the Truck Insurance Exchange in California did pioneering, if unpublished, work on the uses of incident reports in hospitals. See Don Harper Mills \& Orley H. 
These traditional incident reports have been of limited value, however, for insurance claims personnel and risk managers in identifying potential malpractice claims. Traditional reports often define the incidents unclearly and sometimes confuse which incidents should be reported. As a result, hospital reporting patterns vary widely, and completed reports often lack information about the nature and extent of the reported injuries. ${ }^{6}$ Indeed, most traditional incident reports describe errors that were corrected or otherwise had no consequential impact on patient care. Moreover, the reports rarely derive from medical and surgical care-the very occurrences most likely to result in liability and large damages awards. Also, those most involved in delivering such care-physicians-are rarely involved in submitting or screening incident reports under traditional practice. ${ }^{7}$ Because physicians seldom participate and because many fear subsequent discovery of the information through the legal process, more serious occurrences typically go unreported. ${ }^{8}$ Moreover, incident reports are not very selective; literally thousands are filed, very few of which relate to valid claims. Thus, traditional incident reports are neither very specific nor very sensitive as screening tools. They produce a great many "false positives" (reporting cases that do not become claims) as well as "false negatives" (failing to report incidents that become actual claims).

None of this is good news for claims or risk managers. Hence, instead of laboriously sifting through the incident reports, claims personnel traditionally have not opened files and begun resolving claims until they received legal notice, such as a formal letter of intent to sue or some other type of legal notice of an impending or pending law suit. ${ }^{9}$

Lindgren, The Impact of Liability Litigation on the Quality of Care, in James Couch, ed, Health Care Quality Management for the Twenty-First Century (Am Coll Physician Executives, Summer 1991); Don Harper Mills, Orley H. Lindgren, \& Diane Brown, Malpractice Risk Management, in Gary Gitnick, ed, The Business of Medicine: A Physician's Guide (Elsevier Science, forthcoming 1991).

6. Orlikoff, Fifer \& Greeley, Malpractice Prevention and Liability Control for Hospitals at 34-35 (cited in note 4); James E. Orlikoff \& Audrey M. Vanagunas, Malpractice Prevention and Liability Control for Hospitals 55-57 (Am Hosp Ass'n, 2d ed 1988).

7. Physician-owned insurance companies typically maintain separate incident reporting systems. These insurers first appeared in the mid-1970s and rapidly grew to provide a significant portion of physician liability coverage, unrelated to coverage of the hospitals within which the physicians practice. See Frank A. Sloan, Randall R. Bovbjerg \& Penny Githens, Insuring Medical Malpractice (Oxford U Press, 1991). Although there may be cooperation on individual cases, the basic data on hospitals and their emplovees and on physicians are maintained in separate databases.

8. See generally Orlikoff \& Vanagunas, Malpractice Prevention and Liability Control for Hospitals at 55-57 (cited in note 6) ("Although these occurrences justify identification they are of little use in pinpointing patient injuries or areas of risk that may generate a claim or litigation and result in large financial losses for hospitals."). It is also notable that nurses in a typical U.S. community hospital, who take medical orders from independent attending physicians, cannot as readily report on those physicians as on their nursing peers or other matters directly affecting their hospitals.

9. Estimates vary as to what percentage of malpractice actions begin with an incident report. Some publications indicate that the percentage ranges from $5 \%$ to $30 \%$, though these publications are often unclear as to what kinds of reporting are involved and whether all claims from a given type of care are counted. See, for example. American College of Surgeons/Bader \& Associates, Inc., Patient Safety Mamual: A Guide for Hospitals and Physicians to a Systematic .tpproach to Quality Assurance and Risk Management 51-54, 70-72 (Am College of Surgeons, 2d ed 1985); Orlikoff, Fifer \& Greeley, Malpractice Prevention and Liability Control for Hospitals at 36-37 (cited in note 4); Am Hosp Ass'n, 


\section{B. Improving on Traditional Incident Reports}

The need for improved detection of medical malpractice claims has long been clear. A new approach for early detection taken in the 1970s was "generic screening," which originated in the California Insurance Feasibility Study. ${ }^{10}$ The basic idea of early detection is to review hospital records for adverse outcomes caused by medical management. Because so many charts had to be examined to find such relatively rare events, screening criteria were developed by which non-physicians could identify suspect records. The identified records were then reviewed by physicians to determine the presence or absence of patient disabilities caused by health care management. Even with screening criteria, this process proved very expensive to implement for claims detection. Also, it was unfamiliar to hospitals and their staffs, requiring extensive training and continuing education."

Another approach arose from the joint efforts of Los Angeles County 12 and the Professional Risk Management Group ("PRMG"). ${ }^{13}$ Under this approach, incidents are found, described, and preliminarily classified in a onestage reporting system. After classification, independent, professional claims personnel determine which incidents merit investigation or intervention. This approach is the basis for the system and the research described here.

\section{Risk-Management Philosophy in Pro-Active Liability Claims Management}

The basic philosophy of risk management is that medical care providers should detect and immediately report misadventures and hospital-acquired patient injuries with liability potential. ${ }^{14}$ Then immediate investigation and,

Medical Malpractice Task Force Report on Tort Reform and Compendium of Professional Liability Early Warning Systems for Health Care Providers 1.4 (Am Hosp Ass'n, May 1986) (“Task Force Report"); US Gen Acct'g Office, Initiatives in Hospital Risk Management 15-16, 23 (Gov't Printing Office, 1989) (GAO/HRD-89. 79).

10. See Don Harper Mills, David Rubsamen \& John Boyden, Report on the Medical Insurance Feasibility Study for the California Medical Association and Califormia Hospital Association (Sutter, 1977). Don Harper Mills and Jack Fulton (see note 5) developed a system called the Notification System for the California Hospital Association in 1979 using the screening criteria developed in the California Insurance Feasibility Study. Mills converted the screens into specific categories such as cardiac arrest, hemorrhage, pulmonary embolus, and wound disruption. Mills has been affiliated with the Professional Risk Management Group since 1987, serving as a consultant and as medical director.

11. Today occurrence reporting at the departmental level is recommended for quality review. See Paul J. Sanazaro \& Don Harper Mills, A Critique of the Use of Generic Screening in Quality Assessment. 265 J Am Med Ass'n 1977 (April 17, 1991).

12. See Joyce San Jenko, Los Angeles County Risk Management Program (paper presented at the Am Pub Health Ass'n conference, 1976) (available from the U.S. Dept. of Commerce, Nat'l Tech Information Service).

13. The PRMG was founded in 1975 by G. E. von Bolschwing and Sidney Golman as Professional Risk Management, Inc. The firm was established at the direction of Llovds of London and other underwriters and brokers providing excess insurance coverage to large self-insured programs for professional medical and hospital liability in California. By 1983. PRMG was responsible for administering the medical malpractice self-insurance programs for all university teaching hospitals in California except three; by 1987. PRMG was responsible for all but one.

14. Incidents were defined broadly to include any deviation from expected outcomes and any hospital acquired patient injury. Within a few years this definition was being suggested for use by 
in selected cases, active intervention should be undertaken to assist the patient, reduce liability potential, and extract information for purposes of preventing future mishaps. This approach has been taken in California by the PRMG and the major, self-insured California public and teaching institutions to which it provides claims and risk management services.

The concept of "early warning" of malpractice claims, which is a fundamental part of this philosophy, is that adverse events can and should be contemporaneously detected and routinely reported. All medical facility personnel, including physicians and nurses, should join in such reporting. The fact that all the medical facility personnel in the California institutions that now use this approach with the PRMG are employees or agents of the institutions (and thus are covered under the institutions' self-insurance programs) facilitates this joint responsibility. Physicians and other providers are actively involved in the design and periodic upgrading of the early warning system. Physicians in particular have become far more involved in active reporting. Two keys to higher participation have been making the process easier as well as less threatening. Frequent feedback from the PRMG and its promise of better legal defense have also helped encourage participation. Participating physicians are encouraged to report by telephone or face to face with "account executives," who are selected in part for their interpersonal skills. Both the written and oral reports are collected on standard forms, which are then coded by PRMG staff and entered into a dedicated computer system. (In California, the communications to the account executives are protected under confidentiality statutes.) The account executives are frequently on-site, in and around the medical facilities, to carry out investigations, consult with in-house hospital risk managers and staff, and provide various departmental training presentations. The account executives also staff "24-hour hot-lines" to facilitate incident reporting.

The early warning systems trigger active claims and injury management. The account executives work closely with each institution's own risk manager to mitigate both the physical and legal damages in a case. Patients are routinely informed of any problems with their care and are often provided treatment. The relevant portions of their bills are often either deferred or waived by the medical facility. Care providers are encouraged to maintain close communication with the patient and his or her family. When this communication breaks down, the account executive and/or the facility risk manager may meet directly with the patient, family, and their legal representatives, if any, in an attempt to identify and resolve the problems in a non-litigious manner. Such interactions continue until the potential claim is resolved.

Of course, claims initially handled informally sometimes result in the filing of legal claims. Even then, however, the account executives stay actively involved in, and in control of, the claims management process-although

physicians nationally. See Robert H. Brook \& Kathleen N. Williams, Malpractice and the Quality of Care, 8 Annals of Internal Med 836 (1978) 
outside defense counsel is typically retained by PRMG to handle specific legal motions and, as necessary, formal discovery or court proceedings. Throughout, the main emphasis remains on informal cooperation and accelerated investigation and claims resolution.

The information from the investigation and management of malpractice claims and potential claims is used to prevent injury to subsequent patients and to help motivate the medical staff to report future injuries. With successful early warning, such information is available for feedback much sooner than information from medical malpractice claims files that are established more conventionally. When the early warning is first investigated, and again later when the information is extracted from the files and fed back through the medical facilities' committees and educational meetings, the medical staffs are reassured that their reports were useful-that the reports facilitated determining the facts, helping the injured patients, and controlling the facilities' potential liability. The malpractice investigation and management process also provide information that can help a medical department make positive changes for patient care, such as replacing a piece of worn (and dangerous) equipment or identifying and correcting problems of coordination of care.

\section{III}

\section{Data AND Methods}

This article reports on the medical malpractice claims based on incident reports and the risk management system employed in California for selected self-insurance programs that serve public, high-risk teaching facilities. More than thirty health care facilities are included: urban and suburban general medical centers, high risk obstetric and pediatric hospitals, and a variety of other outpatient, ambulatory, and public health clinics. Together, these medical facilities employ several thousand physicians and tens of thousands of other healthcare workers, all of whom are included under their institution's liability coverage. As noted above, claims and risk management services are provided to each of these facilities by the PRMG, which also contributed to the databases used for this article.

These databases include nearly 50,000 reports (telephone and written) and some 8,000 malpractice claims files. ${ }^{15}$ Most of the analyses reported here are based on the claims data, which included 6,706 (84 percent) closed claims and 1,274 (16 percent) open claims from July 1, 1976 through June 30, 1989. About 550 claims were set up each year, ranging from an annual low of 400 claims to a high of 700 claims. The number of claims generally increased during the later years. During the entire period, 6,727 claims were closed. Unless otherwise noted, analyses were performed using both open and closed

15. The exact number of incident reports and claims used in each of the analyses varies because of the different degrees of completeness of the coded information. For example, the year in which the incident occurred was known for somewhat fewer than the full set of claims. 
claims. Analyses of claims' indemnity and expense payments naturally included only closed claims.

Claims analyzed here were restricted to those involving liability that could be characterized as "professional" or "medical." Other types of claims, accounting for less than 3 percent of the original database, were excluded, such as claims involving premises or general liability, workers' compensation, wrongful termination, or auto accidents (in the hospital parking lot, for example). A claim involving a single, directly injured party was counted as one claim regardless of the number of total claimants or the number or type of defendants. Thus, a claim filed by a mother and father, each alleging damages on behalf of their newborn baby, which was brought against the hospital, several doctors, and the nurse and technician, is counted as one claim.

The mode of first notice of a claim was characterized as either "incident report" or "legal notice." Incident reports have already been described. Legal notice includes a letter or other written notice of intent to file a claim, a verified complaint, or the filing of or service of process for a lawsuit. ${ }^{16}$

Before beginning the study, the accuracy of the mode-of-notice computer coding was tested by an independent, retrospective computer matching of incident reports and claims, and by verification with information contained in the manual claims files. All claims data were also subjected to data quality analysis, and any questionable values were confirmed or corrected based on multiple documents in the manual files. Statistical presentations are straightforward univariate presentations of data points or cross tabulations in contingency tables, with chi-square significance testing. ${ }^{17}$

IV

\section{Performance of the Early Warning System}

\section{A. Early Warning and the Speed of Claims Resolution}

1. Early Warning Is Indeed Early. Both the written and telephone incident reports do provide early warning of claims. More than 90 percent of both forms of the reports are made within one week of the adverse event. Fully 95 percent are generated within 30 days. In contrast, under one percent of legal notices arrive within one month of the incident; the majority arrive more than a year after the incident. ${ }^{18}$

16. Initially we categorized the mode of first notice as an external or internal notice. The external notice was almost exclusively legal notice. Other possibilities, not observed, included notification from government agencies. The internal notice came almost exclusively from incident reports-either a telephone incident report or a written incident report. Other possibilities, rarely observed, included occurrence screens and similar screening mechanisms.

17. Most of the chi-square results were significant at greater than the $p=.001$ level, indicating that the pattern of results in the Tables shown were highly unlikely to be due to chance. Detailed statistical results may be obtained from the authors.

18. These data, not presented in tabular form, come directly from the databases described above. Details are available from the authors. 
Just under 600 incident reports were telephoned per year, that is, fewer than six per hospital per month for the entire thirty-facility system monitored here. In contrast, approximately 15,000 reports were written annually, averaging as many as 400 per month for the large $(750$ bed) hospitals. Significantly, the "yield" of claims was higher from telephone reporting. Nearly 30 percent of telephoned reports "triggered" the establishment of a claim file, accounting for fully 32 percent of the total claims established from all forms of notice, whereas less than one percent of written incident reports prompted claims files. ${ }^{19}$ Still, because of their high volume, written incident reports generated about 10 percent of all claims files. In total, incident reports identified approximately 42 percent of claims opened during the fourteen years covered in this article. ${ }^{20}$

2. Early Warning Does Speed Resolution. The speed of incident reporting is only one step in the overall process of resolving medical injury claims. After the telephoned or written report is received, the responsible account executive must investigate the incident and decide whether it is serious enough to warrant creating a malpractice claim file. If so, the executive decides what financial reserve is appropriate and what plan of action is called for to defend or settle the matter. Further time elapses during investigation and settlement negotiations. Other things equal, shorter is better for all concerned. The traditional length of the malpractice settlement process causes emotional stress, takes the parties' away from more productive pursuits, and costs attorneys and insurers money in terms of personnel time as well as lost investment earnings from holding claims reserves in ultrasecure (and lower yielding) accounts. Our data show that the early warning of incident reports speeds claims processing and resolution, and, presumably, will mitigate many of the negative aspects associated with the traditional protracted resolution of medical malpractice claims.

19. These data, not presented in tabular form, are from 1984-85, a period for which more detailed data management systems were in place. Details are available from the authors.

20. Early warning claims, even though they involve first notice by incident reports. sometimes may not arrive very much before subsequent legal notice of the same claim. Although we cannot accurately track the extent to which incident reports subsequently "go legal" under the various circumstances of interest, we estimate that, during a recent period of more intensive claims tracking, at least $17 \%$ of the telephone reported claims and $11 \%$ of the written reported claims have "gone legal." Our next studies will investigate the reliability and validity of this tracking and the reasons that early warning may "go legal" and to what effect. Not all cases of incident reports that later involve claimant lawyers truly have gone legal. For example, with "birth injury claims" or other claims involving minors, account executives often encourage families to seek legal counsel to protect the best interests of the children. 
TABLE $1^{21}$

\section{Time from Incident to Claim Set-Up by Mode of Notice}

\begin{tabular}{cccccccccc} 
& Months to Set-up & \multicolumn{5}{c}{ Percentage Set-Up by Year After Incident } \\
& mean & median & 1st year & 2d year & 3d year & 4th year & 5th year & 6th year \\
$\begin{array}{c}\text { Telephone IR } \\
(\mathbf{n}=2368)\end{array}$ & 7.0 & 6.5 & 91.7 & 6.9 & 0.7 & 0.3 & 0.2 & 0.1 \\
$\begin{array}{c}\text { Written IR } \\
(\mathrm{n}=981)\end{array}$ & 8.2 & 7.3 & 88.1 & 9.2 & 1.4 & 0.6 & 0.3 & 0.4 \\
$\begin{array}{c}\text { Legal Notice } \\
(\mathrm{n}=4610)\end{array}$ & 14.3 & 10.3 & 59.5 & 30.3 & 4.3 & 2.0 & 1.1 & 2.8 \\
& & & & & & & &
\end{tabular}

Table 1 shows that account executives are able to establish a claims file more quickly from an incident report than from legal notices of claims. The average time elapsed is only 7.0 months for telephoned incident reports and 8.2 months for written reports, compared to 14.3 months for legal notice of claims. In each case, the averages are longer than the medians, reflecting the influence of a relatively small share of cases with very slow set-up. Our results are not dissimilar from those reported by earlier studies of closed claims. ${ }^{22}$

Table 1 also shows the pattern of time by year elapsed from incident: the vast majority of incident-report claims ( 88 and 92 percent) were established in the first year after incident; less than 1.5 percent remained to be opened after three years. Conversely, only 60 percent of the legal cases opened within a year, and about 6 percent had not yet opened at the end of three years. ${ }^{23}$

21. There are slightly differing numbers of claims in Tables 1 through 3 because some claims were still open at the time of data collection and because some claims lack a key date. (For Table 1, total cases $=7,459$; Table $2=6,728$; and Table $3=6,706$.) In some cases, the claims file was formally set up at a date after the claim was closed (by settlement or other process). In these cases, the time from claim set-up to claim closed was taken as zero. The result of this coding issue is that the times from incident to set-up are somewhat overstated (Table 1), while those from set-up to closure are understated (Table 2). For all tables, the figures have been rounded to the nearest tenth.

22. A national study of malpractice claims closed in 1975-78 found that just over half of all claims were "reported," that is, files were opened, within a year of incident; 5\% remained unreported after four years. Nat'l Ass'n Ins Commissioners, 2 Malpractice Claims, Final Compilation: Medical Malpractice Closed Claims 1975-1978, 24 Table 1.1 (Nat'l Ass'n of Insurance Commissioners, 1980) ("NAIC Census"). A similar nationwide survey for a sample of 1984 closed claims found that just under half of all claims were filed within a year, and $6 \%$ were not filed by the end of three years. The average time to filing was 16.4 months (median of 13 months). US Gen Acct'g Office, Medical Malpractice: Characteristics of Claims Closed in 1984, 32 (April 1987) (GAO/HRD-87-55) ("GAO Survey").

In drawing comparisons across different claims data, one must always be mindful that insurers and claims adjusters differ in how they define a "claim," that is, under what circumstances they open a file and tabulate data. The GAO survey, for instance, omitted all claims for which no formal demand for payment was made on behalf of a claimant. Id at 15 . Also, the NAIC study predated the wide development of the type of integrated hospital-physician medical centers reported on here, and the GAO survey, based on insurance company data, did not include such self-insured entities. A final source of difference between our results and those of NAIC or GAO is that we have largely urban, high-risk, California hospitals-all factors predisposing toward high claims.

23. The NAIC census reported that $41.7 \%$ of claims were disposed of within one year of report, and $13 \%$ remained to be disposed of after three years. NAIC Census at 27 Table 1.2 (cited in note 22). The GAO survey found that the median time from filing to closure was twenty-three months for claims with payment and seventeen months for those without. Although the average times are not presented, they should be somewhat longer. Just over one-third are resolved within one year, and almost one-quarter take longer than three years. GAO Survey at 33 (cited in note 22). On the dangers of cross-study comparisons, see note 22. 
The speed advantage enjoyed by incident-report claims continued to the settlement stage. As Table 2 shows, incident-report claims were closed faster than legal-notice claims.

\section{TABLE 2}

Time from Claim Set-Up to Claim Closure by Mode of Notice

\begin{tabular}{cccccccccc} 
& Months to Closure & \multicolumn{5}{c}{ Percentage Closure by Year After Set-Up } \\
& mean & median & $<1$ year & 1 year & 2 years & 3 years & 4 years & $5+$ years \\
$\begin{array}{c}\text { Telephone IR } \\
(\mathrm{n}=2129)\end{array}$ & 9.3 & 3.1 & 76.4 & 10.0 & 7.2 & 2.5 & 2.1 & 1.8 \\
$\begin{array}{c}\text { Written IR } \\
(\mathrm{n}=913)\end{array}$ & 5.7 & 1.1 & 86.0 & 7.2 & 3.8 & 1.9 & 0.6 & 0.6 \\
$\begin{array}{c}\text { Legal Notice } \\
(\mathrm{n}=3686)\end{array}$ & 17.8 & 10.6 & 53.0 & 16.7 & 13.5 & 9.2 & 4.0 & 3.8 \\
& & & & & & & &
\end{tabular}

The data show that set-up to closure time periods average well under a year for incident-report claims $(9.3$ months for telephone reports, 5.7 months for written reports). Legal-notice claims, on the other hand, stretch out to an average of 17.8 months before resolution. For the median times, the advantage is even more striking: the median incident report claim closes in three months or less, whereas the median legal notice claim takes more than ten months. The disparity between the means and medians shows that many incident reports are closed quickly, which is consistent with their high rate of closure without indemnity or expenses. In terms of time distribution, three quarters or more of incident-report claims close in the first year after set-up (76 to 86 percent), whereas barely half of legal-notice claims are resolved this quickly (53 percent). Moreover, whereas only about 6 percent of incidentreport claims take more than three years to close, 17 percent of legal-notice claims take this long.

Overall, claims prompted by incident reports average slightly more than a year from incident to resolution, while legal-notice claims average more than thirty-two months. The clear majority of early warning claims (some 60 or 70 percent) were resolved with less than a year's delay from patient injury to payment or other closure. Less than 15 percent of legal-notice claims settle that fast, and more than $\mathbf{1 0}$ percent of legal claims take more then five years to settle, compared to 3 percent or less of incident-report claims. ${ }^{24}$

3. Early Warning Claims Are Faster Despite Having More Severe Injuries. The speed achieved by early warning cases is all the more remarkable because the

24. Again here, comparisons may be sought with the NAIC census and GAO survey. In the 1970 s, overall time from incident to disposition averaged 41.3 months for all claims. However, more severe claims took longer to resolve, and 1978 claims resolved faster than 1975 claims. NAIC Census at 28-29 Table 1.3 (cited in note 22). The GAO did not report overall time to closure.

The speedier process observed for legal-notice claims in our study may in part reflect differences in the number and amounts of paid claims. Compared with the GAO closed claims sample, the legalnotice claims in our study had a smaller portion of claims closed with payment, a smaller proportion of payments exceeding $\$ 100,000$, and no claims with payments exceeding $\$ 1$ million. Details are provided in the next section of this paper. 
TABLE 3

Time from Incident to Claim Closure by Mode of Notice

\begin{tabular}{cccccccccc} 
& $\begin{array}{c}\text { Months to Closure } \\
\text { mean }\end{array}$ & \multicolumn{5}{c}{ Percentage Closure by Year After Incident } \\
median & $<1$ year & 1 year & 2 years & 3 & years & 4 years & $5+$ years \\
Telephone IR & 15.6 & 8.8 & 60.5 & 20.5 & 8.5 & 5.0 & 2.4 & 3.2 \\
$\begin{array}{c}(\mathrm{n}=2126) \\
\text { Written IR }\end{array}$ & 12.5 & 7.4 & 69.7 & 17.2 & 7.1 & 2.6 & 1.6 & 1.7 \\
$\begin{array}{c}(\mathrm{n}=912) \\
\text { Legal Notice } \\
(\mathrm{n}=3668)\end{array}$ & 32.1 & 24.0 & 15.0 & 35.2 & 17.8 & 11.7 & 9.3 & 11.1
\end{tabular}

incident reports, both written and telephoned, involved relatively more serious injuries than the legal-notice claims. Moreover, severity of injury positively correlates with time to resolution; claims for severe injuries take longer to resolve than claims for minor injuries. For this analysis, we relied on the more recent time periods in our data, for which better information was readily available.

\section{TABLE 4}

Rating of Injury Severity by Mode of Notice

$\begin{array}{lccccc} & \begin{array}{c}\text { Percentage } \\ \text { of Total }\end{array} & \text { none* } & \begin{array}{c}\text { Percentage Distribution by Category } \\ \text { minor }\end{array} & \begin{array}{c}\text { moderate } \\ \text { severe }\end{array} \\ \begin{array}{c}\text { Telephone IR } \\ (\mathrm{n}=187)\end{array} & 21.0 & 0.5 & 19.3 & 41.7 & 38.5 \\ \begin{array}{c}\text { Written IR } \\ (\mathrm{n}=67)\end{array} & 7.5 & 0.0 & 31.3 & 37.3 & 31.3 \\ \begin{array}{l}\text { Legal Notice } \\ (\mathrm{n}=636)\end{array} & 71.5 & 4.1 & 26.9 & 45.6 & 23.4 \\ \text { * none }=\text { no ratable physical injury. } & & & & \end{array}$

Simple ratings of severity of injury (from no ratable injury to severe) are made on incident reports at the time they are created. From our sample of 1984-85 incident reports, the most notable finding is that telephone reports are associated with more serious injuries. Of some 600 telephone reports, all but one rated the injuries above "no ratable injury." In contrast, of some 15,000 written reports, nearly 90 percent reported severity of injury as unknown or "no apparent effect," or left the answer blank. Of the 10.5 percent written reports showing some actual injury, 5.4 percent rated severity of injury as "minor" and 5.1 percent rated it as "moderate to severe." However, we do not know how consistent different medical personnel are in arriving at their ratings.

Similar ratings are made in the claims files. Here the evaluations should be more consistent because they are made by the much smaller number of trained account executives. Severity of injury was defined for the account executives as the extent to which an injury caused pain and suffering and either was life threatening or required treatment to be corrected. Permanence of injury was defined as the extent to which an injury, regardless 
of its severity, was likely or not to be correctable either spontaneously or through treatment.

For the 1984-87 claims files (approximately 850 claims), early warning claims involved "minor", "moderate" and "severe" patient injuries. The results suggest that incident reports identify a substantial portion of claims involving some degree of patient injury, including moderate and severe injury. They also suggest that early warning claims have proportionately fewer "nonratable" injuries and proportionately more "severe" injuries than expected; the reverse is true for legal-notice claims. ${ }^{25}$

\section{B. Early Warning and Malpractice Payments}

1. Incident-Report Claims Involve the Full Range of Payment Levels. Just as incident-report claims involve injuries equally severe and permanent as legally initiated claims, if not more so, they also involve high-cost along with low-cost cases. The mean and median costs per claim are quite low when one considers all claims, paid and unpaid.

TABLE 5*

Total Claims Spending

All Closed Claims (paid and unpaid)

Telephone IR

Written IR

Legal Notice

Telephone IR

Written IR

Legal Notice

minimum
$\$ 0$
0
0

minimum

$\$ 20$

25

10 median

$\$ 0$

0

0

mean

$\$ 12.4$

3.6

13.0

maximum

$\$ 913.0$

484.9

903.6

Closed Claims With Some Indemnity Paid

$\begin{array}{ccc}\text { median } & \text { mean } & \text { maximum } \\ \$ 31.1 & \$ 87.4 & \\ 8.6 & 41.1 & 484.0 \\ 16.8 & 60.0 & 903.6\end{array}$

* Dollar amounts expressed are thousands, and include indemnity plus expenses. Amounts are nominal dollars in year paid.

The median for all modes of notice is zero (Table 5), because more than half of all cases are closed without any payment to either the claimant or outside attorneys or investigators for expenses of defense (Table 6). The observed

25. As noted above, the study also examined permanence of injury, which was rated as a separate construct by the account executives. Only one-third of the claims were rated as involving permanent injury, and the contingency table chi-square results were not statistically significant. Thus, early warning claims were not found to be correlated with likelihood of permanent injury.

Severity and permanence of injury are constructs which have been interwoven in scales used in previous studies of malpractice, such as those by the California Insurance Feasibility Study, the NAIC. census, and the GAO survey. Injuries can be categorized as ranging from minor to major independently of the degree to which they are temporary or permanent. For example, a deep laceration of the abdomen may be serious in that it requires major surgery and hospitalization and entails significant costs-yet (if the injured individual is not a fashion model, for example) the individual may have only temporary disability. Our results suggest that the two constructs should be further examined to determine their convergent and discriminate validity, and possibly should be measured separately in future studies 
means are all at or below $\$ 13,000$ per case (Table 5 ). For claims with some indemnity paid, the figures are naturally much higher. Interestingly, telephone incident-report claims score above legal claims, which are themselves higher than written-report claims. This pattern is consistent with the levels of severity noted above (Table 2 ).

TABLE 6

Distribution of Cases by Total Costs and Mode of Notice

$\begin{array}{ccccccc} & \begin{array}{c}\text { Percentage } \\ \text { of Total }\end{array} & \$ 0 & \$ 1-9999 & \$ 10,000+ & \$ 50,000+ & >\$ 99,999 \\ \begin{array}{c}\text { Telephone IR } \\ (\mathrm{n}=2126)\end{array} & 31.7 & 78.4 & 10.3 & 2.4 & 3.5 & 31.7 \\ \begin{array}{c}\text { Written IR } \\ (\mathrm{n}=912)\end{array} & 13.6 & 87.5 & 5.1 & 0.8 & 0.9 & 13.6 \\ \begin{array}{c}\text { Legal Notice } \\ (\mathrm{n}=3668)\end{array} & 54.7 & 53.2 & 30.5 & 2.3 & 3.4 & 54.7\end{array}$

* Includes all closed claims; total payments are not available on open claims. "Total costs" = indemnity plus allocated loss expense.

\section{TABLE 7}

Total Costs by Mode of Notice for Unpaid and Paid Claims

\begin{tabular}{lcccccc} 
& \multicolumn{2}{c}{ Percentage } & \multicolumn{4}{c}{ Percentage Distribution } \\
& Unpaid versus Paid & \multicolumn{4}{c}{ of Paid Claims } \\
& $\$ 0$ & $>\$ 0$ & $\$ 1-9999$ & $\$ 10,000+$ & $\$ 50,000+$ & $>\$ 99,999$ \\
Telephone IR & 78.4 & 21.6 & 47.8 & 25.3 & 10.9 & 16.1 \\
Written IR & 87.5 & 12.5 & 64.9 & 21.9 & 6.2 & 7.0 \\
Legal Notice & 53.2 & 46.8 & 65.3 & 22.5 & 4.8 & 7.3
\end{tabular}

More than 75 percent of telephone-report claims and nearly 90 percent of written-report claims have zero indemnity plus allocated expenses (Table 6). One supposes that this pattern reflects some combination of factors. With early risk management, the need to seek outside counsel, and thus incur additional expense, may be less than where legal notice has already come from outside. Alternatively, account executives may want to be "better safe than sorry" and set up claims files in response to the potential exposure represented by the report's assessment of the level of injury and the estimated degree of liability, with less regard to the actual likelihood that a patient will see an attorney and bring suit (which in any event is very hard to predict).

It is also notable that telephone-report claims seem to contain relatively more cases in the higher ranges (more than $\$ 50,000$ ) -almost 3.5 percent of total cases (the same as for legal-notice claims) - even though less than half as many telephone-report claims involve any cost at all (Table 6). The pattern is clearer on Table 7 where the percentage distribution of cases includes only the non-zero ones. For example, Table 7 examines the 22 percent of telephone-report claims that cost any money then sets out how this subset of claims is shared among cost categories. This array shows more directly that 
the non-zero telephone-report cases (the dominant mode of incident reporting with dollar cost) are different from either the written-report ones or the legal notice cases. That is, telephone-report claims are more costly than legal-notice claims: Whereas two thirds of the legal mode cost between one dollar and $\$ 10,000$, less than half of the incident-report claims fall within that category (Table 7). Similarly, although more than a quarter of telephonereport claims cost more than $\$ 50,000$ per case, less than half that fraction of legal cases are so costly (12.1 percent) (Table 7). The higher relative cost of these incident-report claims may reflect the higher severity of injury involved. Additionally, the low relative cost of legally-initiated claims may reflect small payments to outside counsel, associated to assist with the defense, or to claimants with counsel as a sort of compromise payment. As with the other findings noted above, further analysis is needed here to understand these data more fully.

2. Allocated Expenses Are Relatively Low for Incident-Report Claims. A very frequent complaint about the malpractice liability system is that it costs too much in "overhead," that is, payments to lawyers, investigators, insurers, and others who are not claimants. ${ }^{26}$ One goal of good claims management is to reduce this consumption of resources that could be made available for better uses, including possibly broadening health care services or increasing compensation to injured parties.

The largest single dollar cost of medical liability is that of payments made to claimants, including payments through out-of-court private settlements, court-approved settlements, court judgments (typically on jury verdicts), or arbitrators' awards. ${ }^{27}$ Beyond these payments, costs of malpractice claims include "allocated" costs of investigation and defense, or "allocated loss expense" ("ALE"), which encompasses those costs properly attributable to the management of particular claims. ${ }^{28}$ Normally these costs are external to the claims administrator or insurance company and are therefore readily tracked. ALE includes costs of (1) copying medical records, (2) providing laboratory and medical examination services for claims management (as opposed to direct patient care), (3) transcribing records, (4) obtaining medical experts and reimbursing witnesses, (5) compensating defense

26. See, for example, U.S. Department of Health and Human Services, Report of the Task Force on Medical Liability and Malpractice 19 (HHS, August 1987) ("The present system is widely perceived as expensive to operate. Estimates of the percentage of premiums actually paid out as compensation to victims vary, but it is very likely less than half .... [A] compensation system for medical injury should operate efficiently in terms of financial costs, professional energies, and governmental process.").

27. "Claim severity" is the average indemnity paid on claims, sometimes stated as paid-claims severity, sometimes as a total average, including unpaid claims.

28. See, for example, Randall R. Bovbjerg, et al, Juries and Justice: Are Malpractice and Other Personal Injuries Created Equal, 54 L \& Contemp Probs 5 (Winter 1991). "Unallocated" malpractice claims costs are, as their name implies, the costs not readily attributable to an individual claim, including the administrative overhead of the third-party administrator or insurance company. For rate-making purposes, these costs are added as a proportionate percentage loading. For purposes of this study, unallocated costs are excluded. They would be proportionate to the indemnity and allocated cost in any case. 
counsel, and (6) paying court costs assigned to the defense. Of course, claimants incur additional transaction costs as well (particularly attorneys' fees if successful). Claimant expenses are often assumed to be proportionate to defense expenses. In any event, data on them are not available to us.

The ratio of ALE to total cost (indemnity plus ALE) is a good measure of the transaction cost of the liability system. Our data suggest that the early warning system achieves low ratios of ALE to total cost.

TABLE 8

Ratio of Expenses to Total Claims Cost by Mode of Notice

\begin{tabular}{cccccccc} 
& Total & Total Cases & \multicolumn{5}{c}{ Expense Ratio* by } \\
All Cases & $\begin{array}{c}\text { w/Indemnity } \\
\text { wemnity Paid }\end{array}$ & $\$ 0$ & $\$ 1-9999$ & $\$ 10,000+$ & $\$ 50,000+$ & $>\$ 99,999$ \\
$\begin{array}{c}\text { Telephone IR } \\
(\mathrm{n}=2126)\end{array}$ & 44.8 & 14.2 & 100 & 18.0 & 15.9 & 12.3 & 7.4 \\
$\begin{array}{c}\text { Written IR } \\
(\mathrm{n}=912)\end{array}$ & 41.9 & 14.1 & 100 & 14.7 & 17.1 & 11.9 & 5.2 \\
$\begin{array}{c}\text { Legal Notice } \\
(\mathrm{n}=3668)\end{array}$ & 72.3 & 31.9 & 100 & 43.2 & 25.8 & 19.0 & 11.5 \\
$\begin{array}{c}\text { Total } \\
(\mathrm{n}=6706)\end{array}$ & & & 100 & 36.8 & 22.0 & 16.3 & 9.6
\end{tabular}

" Ratio = allocated loss expense (“ALE”)/(indemnity + ALE), as a percentage.

Overall, ALE of incident-report claims is less than 45 percent of total costs, while ALE of legal-notice claims is more than 70 percent of total costs. This finding was expected, as claims-management policy is to monitor and control outside defense attorney costs and to require account executives to actively control and settle all meritorious cases that can be settled at a reasonable value.

The pattern of low ALE percentages holds true for each category of payment amounts. Especially noteworthy are the claims in which less than $\$ 10,000$ was paid. At this low end of the payment scale, the difference between incident-report claims and legal-notice claims is particularly dramatic: legal-notice claims have an expense "burden" of 43.2 percent, as compared to only 14.7 percent and 18 percent for written-report claims and telephone-report claims, respectively. The expense percentage falls as total costs rise. This pattern is consistent with a high fixed cost for hiring outside counsel, a virtual necessity once a claimant's attorney is involved. Where legal-notice claims are in the lower indemnity range, the ALE ratio is then necessarily high. For all types of notice, ALE ratios decrease as indemnity increases; this pattern is also consistent with high fixed costs of ALE, especially for outside defense attorneys. The relative advantage of incidentreport claims is somewhat lower although still definitely present at the extreme of high indemnity. It may be that both sides spend more heavily when the stakes are clearly high. We expected savings in expense to be greater for "high value" cases, where case management by the account executives is particularly focused because of limits of staff time and a recognition that these cases contribute a disproportionate share to the program's overall expenses. 
ALE ratios for incident-report claims are relatively even lower when only paid claims are counted, 14 percent compared to 32 percent for legal-notice claims. This difference appears to reflect good management of settlement: avoiding lawyers where possible, settling with less protracted litigation, and otherwise holding down costs. Although ALE ratios for all incident-report claims (paid and unpaid) are higher, this may be due to the claims' larger share of zero-indemnity claims, many of which incur some allocated expenses. ${ }^{29}$

\section{Early Warning and Litigation Outcomes}

As might be expected in a program emphasizing settlement of meritorious claims, well over 90 percent of the claims in our study were settled (with or without payment of indemnity) before trial. A small fraction (less than 2 percent) settled during trial. ${ }^{30}$ From a risk management viewpoint, trial results were quite successful: 84 percent were defense verdicts; 16 percent were plaintiff verdicts (but only 6 percent were for more than the pre-trial defense offers). ${ }^{31}$ No verdicts exceeded one million dollars. The majority of cases that are tried to verdict are high-value claims first reported by early warning, particularly by telephone incident reports. These cases are tried because, among other things, they are believed to be non-meritorious or a mutually acceptable settlement value cannot be reached. They may be more defensible, however, because early warning allows the collection of more complete and accurate factual information while it is still fresh, and allows the capture and retention of key pieces of evidence. Early warning also allows the interviewing and tracking of key defense witnesses.

\section{V}

\section{Discussion: Variation in Reporting and Achieving Improvements}

The summary statistics thus far presented do not show variations in performance among sites, among medical specialties, or across time. Such variations help point the way for how early warning systems can be improved. The most basic performance relates to what percentage of subsequent claims are first noticed through incident reports. While some reporting rates are

29. A zero-indemnity claim with ALE raises the ratio of ALE to indemnity plus ALE. The reason is that these claims contribute less to the denominator than do claims with non-zero indemnity and ALE.

These ratios for ALE are higher than for the claims in the GAO survey, although the percentage for paid claims is similar for report-originated claims. GAO Survey at 20-21 (cited in note 22). From its sample, GAO projected ALE of $\$ 807$ million on some 73,000 total claims, with indemnities totalling $\$ 2,566.4$ million on almost 32,000 claims. The ALE ratio for all claims is thus $807 /(2,566.4$ $+807)=23.9 \%$. ALE on paid claims was estimated at $\$ 458.1$ million, so the ratio for closed claims with payment was $458.1 /(2,566.4+458.1)=15.1 \%$. Almost $83 \%$ of ALE was for defense counsel.

30. The GAO reports that $88.1 \%$ of overall claims were disposed of before trial $(94.5 \%$ resolved through conventional legal process), so the statistic comparable to ours is $93.2 \%$ settlement. See GAO Survey at 37 (cited in note 22).

31. On the importance of considering trial outcomes in relation to relative bargaining positions, see Thomas B. Metzloff, Resolving Malpractice Disputes: Imaging the Jury's Shadow, 54 L \& Contemp Probs 43 (Winter 1991). 
very high, others are quite low, which shows that there is considerable room for improvement. ${ }^{32}$

The patterns are striking for what they seem to show about correlates of high reporting rates. Facilities that specialized in acute care in obstetrics and gynecology and in pediatrics reported 68 percent of their claims through early warning, 46 percent of which were reported by telephone. ${ }^{33}$ Given the high profile of obstetricians and "bad baby" cases in malpractice experience, heightened use of the reporting system seems understandable. The results for facilities with these specialties are encouraging, because these facilities may constitute model programs for educating medical staffs to participate actively in both incident reporting and in feedback of information to practitioners.

Similarly dramatic differences in the extent of the use of early warning existed in nineteen groupings of medical specialties. For physicians as for hospitals, not surprisingly, obstetrics, gynecology, and pediatrics were among those specialties with the highest rate of claims identification (regardless of the type of facility). Nearly half of their claims were identified through telephone reports and more than 10 percent through written reports. Highest of all physician specialties was anesthesia, with 73 percent of their claims identified through early warning ( 59 percent by telephone). Among occupations, nursing had the highest percentage of claims identified through incident reports, 74 percent early warning, with 45 percent by telephone. ${ }^{34}$ The high extent of early warning in anesthesia and in obstetrics and gynecology may be explained by the fact that these specialties have been the focus of concentrated programs to educate medical staffs as to their high malpractice liability exposure and to encourage the staffs' active participation in the early warning reporting and investigation activities carried out by hospital risk management and the PRMG.

Claims for 1978 through 1983 were predominantly reported first through early warning (55 to 60 percent of claims, with 36 to 46 percent by telephone). For 1984 to 1988, early warning was approximately 40 percent of claims annually. The change in 1983 is understandable. That year marked a retrenchment among California academic/public hospitals as they coped with cutbacks in MediCal eligibility and rate cuts under California's competitively negotiated payment contracts. Given significant staffing cuts and increases in medically indigent patients requiring services, "extra" activities such as incident reporting were reduced. One cutback imposed during this period was on the financing of pro-active risk management activities, with the claims administrator having to devote more time to managing high-value litigation claims. Current demonstration-evaluation activities are underway to examine

32. The effectiveness of early warning is now being routinely tracked, so that future analyses will not have to be retrospective, as is this one

33. From a base of 1,269 such claims, we are statistically confident that these results are not due simply to chance.

34. Similarly dramatic results were found for specialty groupings (including several of the surgeries) whose claims were almost all established through legal notice rather than early warning. 
the extent to which the quantity and quality of early warning can be increased to pre-1983 levels. ${ }^{35}$ Claims administration is also being targeted. More detailed examination of the quality of incident reports is called for, as well as probing the claims administrator's structure and process of translating incident reports into claim files. ${ }^{36}$

Quantitative data of the type this article has begun to develop not only point to areas needing improvement, but they also suggest how much improvement might be expected. For example, lesser-reporting groups can be held to the standard of their higher-reporting peers. Moreover, examination of recently tracked legal-notice claims suggests that both reporting and reviewing incident reports could be improved. Retrospectively, 25 percent of the legal-notice claims were designated as having arisen from incidents that "should have been reported but were not." Another 35 percent actually had incident reports that should have been the basis for establishing claims files but in fact were not. Thus, for the institutions and personnel covered in this article's data, perhaps as many as 200 additional legal-notice claims could have been identified annually through better early warning.

\section{VI}

\section{Conclusion}

Risk managers have long suggested that early identification of potential liability claims through incident reporting could improve the prognosis of injured parties, the performance of the liability system, and the well-being of potential defendants. Many have also argued that faster and cheaper resolution helps all parties and should be attainable. ${ }^{37}$ This article has offered the first published empirical analyses to confirm this risk-management creed.

Several points about early warning deserve final emphasis. In design and execution, the type of early warning described in this article, based on careful use of incident reports, differs from traditional incident reporting in a number of ways. Perhaps the key difference is the active cooperation of the full hospital medical staff. Physician involvement is crucial for generating prompt information about serious injuries, which disproportionately involve physician-related care. A good claims- and risk-management staff is also essential to this type of enhanced participation.

35. The goal is to improve both the process of creating reports and the process of reviewing and making decisions to establish claim files on the basis of these reports.

36. These steps include: (1) increasing the frequency of in-service education programs for medical staff, emphasizing the value and ease of incident reporting; (2) improving the various printed charts, tables, and other reports that can be computer generated from the incident reports and claims databases and routinely "fed back" to medical staff for motivational and educational purposes; and (3) streamlining the process of coding, key entry, and review of incident reports.

37. Am Hosp Ass'n, Task Force Report at 4 (cited in note 9) ("In October 1985, the board of directors of the American Society for Hospital Risk Managers of the American Hospital Association voted to endorse the use of professional liability early warning systems as an essential component of all comprehensive, hospitalwide risk management programs."). 
The rationale for promoting early warning is that "forewarned is forearmed." As noted above, with the most dangerous exposure pin-pointed early, claims management can (1) assemble relevant facts rapidly and systematically while they are fresh; (2) identify and preserve relevant documentary and material evidence; (3) take prompt action to define and mitigate both patient injury and legal damages; $(4)$ try to "make things right," perhaps with appropriate apologies, tender of remedial care, or waiver of bills; and (5) generally attempt to forestall the emotional mind-set that seeks vindication through formal legal proceedings. Finally, after ultimate resolution of cases, pro-active management calls for tabulating results, deriving lessons, and constantly re-educating clients and risk-management professionals alike.

This article has presented preliminary descriptive results from over a decade's experience with early-warning risk management in thirty institutions. From this, it appears definite that incident reports, especially those telephoned in, generate early warning in a large share of cases, although it could be larger still. With a head start, the entire claims resolution process moves more quickly than when it must await legal notice. Early warning also lowers the "overhead" of claims resolution. Non-indemnity expenses are lower in incident-report claims as a share of total cost than in legal-notice claims. These beneficial results are achieved not just for the small incidents traditionally reported, but also for a population of claims with more severe injuries and even higher indemnities than found in legal-notice claims. Further, legal outcomes are at least comparable to national norms in avoiding trials and winning favorable verdicts.

Despite these favorable data, more needs to be learned. Information can be improved about how early-warning risk management works and what further steps can make it work more effectively. More basic and applied research is needed on how information developed by risk managers can be used to prevent patient injury. ${ }^{38}$ We also would benefit from documenting the extent to which early warning works in other healthcare settings and in other states. Although much work remains to be done to forge a strong discipline and a successful relationship, for risk managers and their clients alike, the future offers considerable promise for the still youthful profession of risk management.

38. Thus far, there are conceptual as well as practical reasons to expect feedback to be effective in helping medical professionals make appropriate changes, but practical implementation needs constant effort. 
